$7-2006$

\title{
Assessment of Pneumonia in Older Adults: Effect of Functional Status
}

Lona Mody

Rongjun Sun

Cleveland State University, r.sun32@csuohio.edu

Suzanne F. Bradley

Follow this and additional works at: https://engagedscholarship.csuohio.edu/clsoc_crim_facpub

Part of the Demography, Population, and Ecology Commons, and the Medicine and Health Commons How does access to this work benefit you? Let us know!

Publisher's Statement

(c) 2006 Wiley-Blackwell

\section{Original Citation}

Mody, L., Sun, R., , \& Bradley, S. F. (2006). Assessment of Pneumonia in Older Adults: Effect of Functional Status. Journal of the American Geriatrics Society, 54(7), 1062-1067.

\section{Repository Citation}

Mody, Lona; Sun, Rongjun; and Bradley, Suzanne F., "Assessment of Pneumonia in Older Adults: Effect of Functional Status" (2006). Sociology \& Criminology Faculty Publications. 19.

https://engagedscholarship.csuohio.edu/clsoc_crim_facpub/19

This Article is brought to you for free and open access by the Sociology \& Criminology Department at EngagedScholarship@CSU. It has been accepted for inclusion in Sociology \& Criminology Faculty Publications by an authorized administrator of EngagedScholarship@CSU. For more information, please contact library.es@csuohio.edu. 


\title{
Assessment of Pneumonia in Older Adults: Effect of Functional Status
}

\author{
Lona Mody, MD, MSc, ${ }^{* \ddagger}$ Rongiun Sun, PhD, ${ }^{\mathcal{S}}$ and Suzanne F. Bradley, MD ${ }^{* \dagger \neq}$
}

OBJECTIVES: Evaluate the effect of preadmission functional status on severity of pneumonia, length of hospital stay (LOS), and all-cause 30-day and 1-year mortality of adults aged 60 and older and to understand the effect of pneumonia on short-term functional impairment.

DESIGN: Prospective cohort study.

SETTING: University hospital.

PARTICIPANTS: One hundred twelve patients with radiograph-proven pneumonia (mean age 74.6) were enrolled.

MEASUREMENTS: Functional status and comorbidities were assessed using the Functional Autonomy Measurement System (SMAF) and Charlson Comorbidity Index. Clinical information was used to calculate the Pneumonia Prognostic Index (PPI).

RESULTS: Eighty-four (75\%) patients were functionally independent (FI) before admission, with a SMAF score of 40 or lower. Dementia and aspiration history were higher in the group that was functionally dependent (FD) before admission $(P<.001)$. The FI group had less-severe pneumonia per the PPI and shorter mean LOS \pm standard deviation $(5.62 \pm 0.51$ days) than the FD group (11.42 \pm 2.58 , $P<.004)$. The FI group had lower 1 -year mortality (19/ $65,23 \%)$ than the FD group $(14 / 28,50 \%)$, and the difference remained significant after adjusting for Charlson Index and severity of illness $(P=.009)$. All patients lost function after admission, with loss being more pronounced in the FI group (mean change $19.24 \pm 12.9$ vs $4.72 \pm 6.55$, $P<.001)$.

CONCLUSION: Older adults who were FI before admission were more likely to present with less-severe pneumonia and have a shorter LOS. In addition, further loss of function was common in these patients. Assessment of function before and during hospitalization should be an integral part of clinical evaluation in all older adults with pneumonia. J Am Geriatr Soc 54:1062-1067, 2006.

From the Divisions of * Geriatric Medicine and ${ }^{\dagger}$ Infectious Diseases, Department of Veterans Affairs Ann Arbor Healthcare System, Ann Arbor, Michigan; ${ }^{\ddagger}$ Medical School, University of Michigan, Ann Arbor, Michigan; and ${ }^{\$}$ Department of Sociology, Cleveland State University, Cleveland, Ohio.

Address correspondence to Lona Mody, MD, 11G GRECC, Ann Arbor VA Healthcare System, 2215 Fuller Road, Ann Arbor, MI 48105.

E-mail: lonamody@umich.edu
Key words: pneumonia; functional assessment; older adults

T he incidence of pneumonia in the United States has been estimated at 4 million cases annually, with $20 \%$ of episodes requiring hospitalization. ${ }^{1}$ Hazards of hospitalizing older patients have been well documented. ${ }^{2}$ Hospitalized older patients are at risk for developing complications such as falls, incontinence, and delirium. Functional deterioration occurs quickly after admission in a significant proportion of hospitalized older patients and typically fails to improve by the time of discharge. ${ }^{3}$

Studies of the effect of function on pneumonia outcomes in older adults have drawn conflicting conclusions. ${ }^{4,5}$ In a prospective study to evaluate risk factors for mortality from lower respiratory tract infections in nursing home residents, it was concluded that activity of daily living (ADL) dependency was an important predictor of mortality. ${ }^{4}$ Similarly, in a prospective study of pneumonia in a Department of Veterans Affairs facility, functional status was found to be a major determinant of survival after pneumonia. ${ }^{5}$ Alternatively, from a prediction model of 30day mortality from pneumonia, functional status was not found to be a significant predictor of mortality in nursing home residents. ${ }^{6,7}$ Few studies have assessed the effect of functional status on pneumonia severity in hospitalized older adults. ${ }^{8,9}$ In a prospective evaluation of pneumonia in hospitalized community-dwelling older adults and nursing home residents, authors noted that pneumonia mortality was higher in the nursing home residents, but this was mainly attributed to poor baseline functional status. ${ }^{8}$ Functional status was an independent predictor of short-term and long-term mortality from pneumonia in a study that focused on older adults evaluated in an emergency department setting. ${ }^{9}$

The main objective of the current study was to examine the role of preadmission functional status on pneumonia severity through assessment of pneumonia presentation, length of stay (LOS), and 30-day mortality of adults aged 60 and older admitted to a university-based hospital. The secondary objective was to understand the effect of an acute 
infection such as pneumonia on short-term functional impairment.

\section{METHODS}

\section{Study Population}

Individuals aged 60 and older admitted from the emergency department to the University of Michigan Medical Center from January 1, 2000, to December 31, 2001, with primary or secondary diagnosis of possible pneumonia were screened. The University of Michigan institutional review board approved the project, and informed consent was obtained from the subjects or a proxy with power of attorney. Patients hospitalized with radiograph-proven pneumonia were included in the study. Reasons for exclusion were refusal to give informed consent, transfer from another hospital, acute care hospitalization within previous 15 days, and other diagnosis deemed responsible for admission, such as congestive heart failure, exacerbation of chronic obstructive pulmonary disease, urosepsis, lung cancer, noninfective pleural effusion, bronchiectasis, and "possible pneumonia" that did not fulfill criteria.

\section{Definition of Pneumonia}

Pneumonia was diagnosed using standard criteria, including chest radiograph demonstrating pneumonia, probable pneumonia, or the presence of a new infiltrate and the presence of at least two of the following symptoms and signs compatible with pneumonia: (1) new or increased cough; (2) new or increased sputum production; (3) fever $\geq 100.4^{\circ} \mathrm{F}$; (4) pleuritic chest pain; (5) new or increased physical findings on chest examination (rales, rhonchi, wheezes, bronchial breathing); or (6) one of the following indications of change in the status or difficulty in breathing (new or increased shortness of breath, respiratory rate $>25$ breaths per minute, or worsening mental or functional status). ${ }^{10}$

\section{Data Collection}

\section{Clinical and Demographic Data}

Patients were interviewed within 48 hours of diagnosis to obtain demographic and clinical data to ascertain their risk factors for pneumonia. History of alcohol use, smoking, asthma, lung disease, cardiac disease, malignancies, diabetes mellitus, renal insufficiency, liver disease, aspiration (as documented in the chart or history by a caregiver), seizure disorder, dementia, and other neurological disorders were assessed. History of presenting clinical findings, including fever, cough, sputum production, pleuritic chest pain, new falls associated with illness onset before admission, confusion, and loss of appetite, were obtained in face-to-face interviews with the patient or the caregiver. Vital signs and laboratory findings on admission were recorded. Thirty-day and 1-year mortality were assessed using subsequent chart review.

\section{Assessment of Functional Status and Comorbidity}

Preadmission functional status ( $\geq 1$ weeks before onset of illness) was assessed by interviewing the patient, caregiver, or both using the Functional Autonomy Measurement System (SMAF), which is a 29 -item scale that measures func- tional ability in five areas: ADLs (eating, washing, dressing, grooming, urinary and bowel function, using toilet), mobility (transfers, walking, donning prosthesis, propelling wheelchair), communication (vision, hearing, speaking), cognitive function (memory, orientation, comprehension, judgment, behavior), and instrumental ADLs (housekeeping, meal preparation, shopping, laundry, telephone, transportation, medication use, finances). ${ }^{11,12}$ Each item was scored on a 4-point scale from 0 (independent) to 3 (dependent). Patients were stratified into two groups; those with a score of 40 or less were considered to be functionally independent (FI) and those with a score greater than 40 were considered to be functionally dependent (FD) before admission. ${ }^{11,12}$ It was anticipated that community-dwelling older adults with pneumonia would be independent with their ADLs. Measuring only ADLs in this population would be inadequate. Preadmission and admission SMAF scores were compared to assess change in functional status. A change of 5 points was considered to be a significant change in functional status. The Charlson Comorbidity Index was used to assess comorbidity. ${ }^{13}$

\section{Assessment of Severity of Pneumonia}

Using clinical information, the Pneumonia Prognostic Index (PPI) score for each patient was calculated and a weighted score with points assigned for age, sex, nursing home residence, coexisting illnesses, physical findings, and laboratory and radiographic findings. ${ }^{14}$ According to their score, patients were classified as being in one of the five classes: Class 1 (age 50, no coexisting conditions, laboratory abnormalities, or physical findings), Class 2 ( $<70$ points), Class 3 (71-90 points), Class 4 (91-130 points), and Class 5 (>130 points).

\section{Outcomes}

The primary outcomes were LOS, severity of pneumonia at presentation, and 30-day and 1-year all-cause mortality. The secondary outcome was functional decline due to pneumonia.

\section{Statistical Methods}

Data were entered into Excel (Microsoft Corp., Redmond, WA) and analyzed using SAS statistical software (Version 8.2, SAS Institute, Inc., Cary, NC). Univariate analysis was carried out using the chi-square test for categorical data and the Student $t$ test for continuous variables.

Associations between SMAF scores before and at admission for individual patients were examined using paired $t$ test. Because the statistical analysis showed that the variance of the SMAF scores was not constant, the unequal variance test design was used.

Preliminary analysis showed that LOS was left skewed. To alleviate such skewness, a logarithm transformation for this variable was applied. A multiple log-linear model was used to evaluate differences in the LOS after controlling for Charlson Comorbidity Index and severity of illness at presentation between FI and FD older adults. These covariates were selected, because they could confound the association between premorbid functional status and LOS.

A logit model was applied to investigate 30-day and 1year mortality. The logit of the probability of death was 
assumed to depend on the functional status and severity of pneumonia at presentation. $P<.05$ was considered significant.

\section{RESULTS}

\section{Patient Characteristics}

Two hundred ninety-five patients admitted with primary or secondary diagnosis of possible pneumonia were evaluated further for inclusion in the study. Reasons for subsequent exclusion were congestive heart failure $(\mathrm{n}=35)$; recent admission $(\mathrm{n}=30)$; chronic obstructive pulmonary disease $(\mathrm{n}=27)$; other lung pathology, including lung cancer, bronchiectasis, noninfectious pleural effusion, and active tuberculosis $(n=22)$; urinary tract infection and urosepsis $(\mathrm{n}=21)$; possible pneumonia that did not fulfill the definition $(n=18)$; transfer from outside hospital $(n=13)$; pulmonary embolism $(n=9)$; refusal to have subsequent evaluation of function $(\mathrm{n}=6)$; and refusal to give informed consent for inclusion in the study $(\mathrm{n}=2)$.

Overall, 112 hospitalized patients (mean age \pm standard deviation $74.6 \pm 9.72)$ were enrolled in the study (Table 1). Eight-four patients $(75 \%)$ were in the FI group and $28(25 \%)$ were in the FD group. Eighty-eight patients resided in the community, 19 were admitted from a nursing home, and five came from assisted living. Mean Charlson Comorbidity Index was $2.97 \pm 2.07$, and mean PPI score was $117 \pm 31$ (range 61-218). Thirty (27\%) patients had a history of dementia, $55(49 \%)$ had a history of prior pneumonia, and $65(58 \%)$ were admitted with severe pneumonia, falling into severity Classes 4 and 5. Sixty-four (57\%) of the patients had been immunized with pneumococcal vaccine, and $74(66 \%)$ had received the influenza vaccine.

\section{Preadmission Functional Status and Symptoms at Presentation}

New or increased confusion, loss of appetite, and new falls were common presenting symptoms in both groups, with confusion being more common in the FD group (Table 2). A significantly greater proportion of the FD group had a history of aspiration documented in the chart or by a caregiver than of the FI group (21/28 (75\%) vs $23 / 84(27 \%)$; relative risk $=2.74, P<.001)$. Pleurisy was more com- monly reported in the FI group (31/84 (37\%) vs $2 / 28$ (7\%), $P=.004)$.

\section{Preadmission Functional Status and Clinical Outcomes of Pneumonia}

Forty-eight percent (40/84) of the FI group and 25\% (7/28) of the FD group presented with less-severe pneumonia (PPI Classes 2 and 3) $(P=.03)$. Twenty-nine percent $(8 / 28)$ of the FD group with pneumonia required an intensive care unit admission, compared with $13 \%(11 / 84)$ of the FI group $(P=.06)$.

The FI group had lower 30-day mortality (12/84 $(14.2 \%))$ than the FD group $(9 / 28(32 \%))$; the difference was not statistically significant when severity of illness and comorbidity score were added to the model $(P=.07$, Table $3)$. The FI group had lower 1-year mortality $(19 / 65(23 \%))$ than the FD group $(14 / 28(50 \%))$, and the difference remained significant when Charlson Comorbidity Index and severity of illness were added to the model $(P=.009$, Table 3$)$.

Mean LOS was significantly lower in the FI group $(5.87 \pm 4.97$ days $)$ than in the FD group $(9.82 \pm 10.98$ days). This difference remained statistically significant after adjusting for severity of illness and Charlson Comorbidity Score $(P=.03)$.

\section{Loss of Function on Admission}

Preadmission functional status was compared with functional status at the time of hospital admission for both groups. Mean SMAF score increased from 12.90 preadmission to 32.44 (mean difference 19.24 \pm 12.96 ) on admission in the FI group, indicating a substantial decline in function as a result of the infection. In contrast, in the FD group, mean SMAF score increased slightly, from 59.20 preadmission to 64.00 on admission (mean difference $4.72 \pm 6.55)$.

\section{DISCUSSION}

The results show that preadmission function, as measured using the SMAF, a comprehensive functional status instrument, is an important determinant of outcome from pneumonia and strengthens predictions based on severity of illness and comorbidities. Several results support this con-

Table 1. Baseline Clinical and Demographic Characteristics of Older Adults with Pneumonia $(\mathrm{N}=112)$

\begin{tabular}{lccc}
\hline \multicolumn{1}{c}{ Characteristic } & $\begin{array}{c}\text { Functionally } \\
\text { Independent } \\
(\mathrm{n}=84)\end{array}$ & $\begin{array}{c}\text { Functionally } \\
\text { Dependent } \\
(\mathrm{n}=28)\end{array}$ & $P$-value \\
\hline Age, mean \pm SD & $74.32 \pm 9.9$ & $74.86 \pm 10.3$ & .9 \\
$\begin{array}{l}\text { Sex, } \mathrm{n} \\
\text { Male }\end{array}$ & 30 & 15 & .09 \\
$\quad$ Female & 54 & 13 & .6 \\
Charlson Comorbidity Index, mean \pm SD & $2.94 \pm 2.1$ & $3.18 \pm 2.0$ & $.045^{*}$ \\
PPI score, mean \pm SD & $113.9 \pm 29.04$ & $127.4 \pm 34.4$ & $.03^{*}$ \\
PPI class distribution, $n(\%)$ & & & \\
2 and 3 & $40(48)$ & $21(25)$ & \\
4 and 5 & $44(52)$ & & \\
\hline
\end{tabular}

${ }^{*} P<.05$.

$\mathrm{SD}=$ standard deviation; PPI $=$ Pneumonia Prognostic Index. 


\begin{tabular}{|c|c|c|c|c|}
\hline \multirow[b]{2}{*}{ Clinical Presentation } & $\begin{array}{c}\text { Functionally } \\
\text { Independent } \\
(\mathrm{n}=84)\end{array}$ & $\begin{array}{c}\text { Functionally } \\
\text { Dependent } \\
(\mathrm{n}=28)\end{array}$ & \multirow{2}{*}{$\begin{array}{c}\text { Relative Risk } \\
\text { (95\% Confidence } \\
\text { Interval) }\end{array}$} & \multirow[b]{2}{*}{$P$-value } \\
\hline & \multicolumn{2}{|c|}{$\mathrm{n}(\%)$} & & \\
\hline History of aspiration & $23(27)$ & $21(75)$ & $2.74(1.8-4.1)$ & $<.001^{*}$ \\
\hline Prior pneumonia & $46(55)$ & $9(32)$ & $0.59(0.3-1.0)$ & .06 \\
\hline Pneumococcal vaccine & $53(64)$ & $11(39)$ & $0.93(0.6-1.4)$ & .69 \\
\hline Influenza vaccine & $59(70)$ & $15(54)$ & $1.03(0.8-1.4)$ & .83 \\
\hline New or increased cough & $71(85)$ & $23(82)$ & $0.97(0.8-1.2)$ & .77 \\
\hline Sputum production & $55(66)$ & $15(54)$ & $0.82(0.6-1.2)$ & .26 \\
\hline New or increased dyspnea & $70(83)$ & $21(75)$ & $0.9(0.7-1.1)$ & .33 \\
\hline Pleurisy & $31(37)$ & $2(7)$ & $0.26(0.1-0.8)$ & $.004^{*}$ \\
\hline Fever & $47(56)$ & $17(61)$ & $1.09(0.78-1.5)$ & .66 \\
\hline Hypotension (systolic blood pressure $<90 \mathrm{mmHg}$ ) & $11(13)$ & $8(29)$ & $2.18(1.0-4.9)$ & .06 \\
\hline Tachycardia (heart rate $>125$ beats $/ \mathrm{min}$ ) & $21(25)$ & $9(32)$ & $1.29(0.7-2.5)$ & .46 \\
\hline New or increased confusion & $23(27)$ & $19(68)$ & $2.48(1.6-3.8)$ & $<.001^{*}$ \\
\hline Loss of appetite & $60(71)$ & $21(75)$ & $1.05(0.8-1.4)$ & .72 \\
\hline New falls & $19(23)$ & $8(29)$ & $1.25(0.6-2.5)$ & .55 \\
\hline
\end{tabular}

${ }^{*} P<.05$.

clusion. First, the results show that previously independent older adults are more likely to present with less-severe pneumonia as measured using the PPI. Second, these FI older adults have a shorter LOS after adjustment for severity of illness. These findings suggest that incorporating measures of functional status into patient assessments may improve the ability of these risk classification systems to predict outcomes from an acute infection such as pneumonia, especially in those aged 60 and older.

Controversies persist as to the degree to which age influences the clinical presentation of pneumonia. Differences in baseline functional status or comorbid illness may, in part, explain some of these discrepancies. ${ }^{15-18} \mathrm{~A}$ few studies have found that symptoms such as cough and sputum production were no less common in patients aged 65 and older than in younger patients, ${ }^{19-21}$ but in elderly veterans, a group typically characterized as having more comorbid illness, it was found that the typical triad of cough, fever, and dyspnea was present in only $56 \%$ of a study cohort. ${ }^{5}$ The findings from the current study show that typical presentation of pneumonia is more common in FI older adults than in FD older adults.

What are the implications of differences in symptom reporting in older adults with differing functional status? Early diagnosis and treatment of pneumonia are critical for successful management of pneumonia. FI older adults present with more-typical pulmonary symptoms and therefore may have earlier diagnostic evaluation and initiation of treatment. A focus on earlier diagnosis of pneumonia in older adults with preadmission functional dependency, even in the absence of typical symptoms, might lead to earlier treatment and better outcomes.

Various studies have shown that nursing home-acquired pneumonia differs from community-acquired pneumonia with respect to its prognosis and outcomes. ${ }^{18,21-23}$ Residence in nursing homes is one of the variables used to assess pneumonia severity in the PPI. Nursing homeacquired pneumonia is considered to be a poor prognostic factor when adjusted for disease severity but not when adjusted for functional status. ${ }^{8}$ This is an important distinction and suggests that poor functional status (or the resultant delayed diagnosis and transfer) is the main factor that explains higher mortality with nursing home-acquired pneumonia. Inclusion of premorbid functional status in the PPI might be a better marker for poor outcome rather than place of residence per se.

These results may not come as a surprise. Some previous studies have found relationships between functional status and mortality in older adults, whereas others have not. ${ }^{4-9}$ In older people, functional status measures, includ-

Table 3. Preadmission Functional Independence and 30-Day and 1-Year Mortality of Older Adults Admitted with Pneumonia

\begin{tabular}{lllllll}
\hline & \multicolumn{3}{c}{ Crude } \\
\cline { 2 - 7 } Mortality & \multicolumn{4}{c}{ Odds Ratio $(95 \%$ Confidence Interval) $P$-value } \\
\hline 30-day & 0.35 & $(0.13-0.96)$ & .04 & 0.39 & $(0.14-1.10)$ & .07 \\
1-year & 0.29 & $(0.12-0.72)$ & .007 & 0.29 & $(0.11-0.73)$ & .009 \\
\hline
\end{tabular}

* Logit model, adjusted for severity of illness and Charlson Comorbidity Index. 
ing physical, cognitive, and social functioning, have been shown to be important predictors of hospital outcomes, including functional decline, LOS, institutionalization, and death due to any cause. ${ }^{24}$ In a retrospective chart review, 400 medical intensive care unit patients aged 50 and older were studied to examine the predictors of hospital and 6month mortality. Of patients without functional limitations, the oldest group $(\geq 75)$ was no more likely to die than the youngest, but the oldest group with functional limitations was more likely to die in the hospital than were those aged 50 to 64 without functional limitations. ${ }^{25}$ A similar conclusion was reached when examining the factors that predict outcome of nursing home residents with lower respiratory tract infections. ${ }^{4,26}$

Functional loss occurred even in FI older adults, despite less-severe illness and shorter LOS. Functional loss was more pronounced in patients with higher preadmission function. These findings could very well be due to "ceiling effect"; patients with higher function had more to lose. The ceiling effect was also observed in a study evaluating predictors of short-term functional decline after lower respiratory infections in nursing homes. ${ }^{27}$ This study showed that moderate ADL impairment at baseline was the strongest predictor of further decline after an episode of lower respiratory infection, perhaps because they had more room to decline. Assessment of function and decline thereof due to infection has implications for discharge planning for older adults. In a study of patients at low risk of poor outcomes based on PPI, $31 \%$ of hospitalized patients with pneumonia were unable to eat or drink enough to maintain hydration by hospital Day 5 or on discharge day. ${ }^{28}$ These studies further underscore the importance of functional status assessments in research and clinical care involving older adults. ${ }^{29}$

The importance of functional status as a predictor of specific clinical outcomes has vital implications for users of prognostic markers and risk indices. For example, risk indices are used to compare quality indicators across providers and outcomes for community-acquired pneumonia. ${ }^{30} \mathrm{In}$ such situations, use of functional status measures may be used to account for baseline differences in assessing outcomes. In addition, risk indices are often used to compare outcomes in clinical trials. The findings of the current study suggest that collecting functional status information at baseline will improve these comparisons.

A few limitations of this study should be acknowledged. The observational study design could have introduced bias that it was not possible to adjust for with the severity-of-illness indices and functional status measurements. The sample size of this study did not conclusively prove that poor preadmission functional status was an independent predictor of 30-day mortality after adjusting for severity of pneumonia and comorbidities, although there was a trend in that direction. This was a prospective hospital-based study and included patients who were more severely ill than those treated in the community and excluded patients with pneumonia treated in an outpatient setting or those in nursing homes with advanced dementia precluding treatment. Any potential influence of specific pathogens in causing functional decline was beyond the scope of this study and was not evaluated. Patient and family preferences for treatment were not captured in the study, and these could have influenced the performance of other processes of care that, in turn, could have affected patient outcomes. Patients with advance directives, do-not-resuscitate orders, or less than full code status could have received less-aggressive testing and treatment, and these confounding factors could have been unequally distributed between patients with or without functional dependence.

In conclusion, FI older adults hospitalized with pneumonia are more likely to present with typical respiratory symptoms and less likely to display atypical symptoms such as confusion than FD older adults with pneumonia. Those with intact functional status with pneumonia have clinically less-severe disease than FD individuals with pneumonia. Assessment of function should be an integral part of clinical evaluation and risk assessment of older adults with pneumonia to monitor outcomes, assess effectiveness and quality of care provided, and aid in discharge planning.

\section{ACKNOWLEDGMENTS}

Financial Disclosure: This work was supported by the American Federation for Aging Research. Dr. Mody is also funded by National Institute on Aging Grant K23 AG022463 and an American Geriatrics Society/Association of Subspecialty Professors T. Franklin Research Scholar Award.

Author Contributions: Lona Mody: study concept and design; enrollment of subjects; data acquisition, management, analysis, and interpretation; manuscript preparation. Rongjun Sun: data management, statistical analysis and interpretation, critical review. Suzanne F. Bradley: study concept and design, interpretation of data, critical review.

\section{Sponsors' Role: None.}

\section{REFERENCES}

1. Kozak LJ, Lawrence L. National Hospital Discharge Survey: Annual summary, 1997. Vital Health Stat 1999;13:144-146.

2. Creditor MC. Hazards of hospitalization of elderly. Ann Intern Med 1993;118:219-223.

3. Inouye SK, Wagner DR, Acampora D et al. A predictive index for functional decline in hospitalized elderly medical patients. J Gen Intern Med 1993;8:645652 .

4. Mehr DR, Zweig SC, Kruse RL et al. Mortality from lower respiratory infection in nursing home residents. A pilot prospective community-based study. J Fam Prac 1998;47:298-304.

5. Muder RR, Brennen C, Swenson DL et al. Pneumonia in a long-term care facility. A prospective study of outcome. Arch Intern Med 1996;156:23652370 .

6. Naughton BJ, Mylotte JM, Tayara A. Outcome of nursing home-acquired pneumonia: Derivation and application of a practical model to predict 30 day mortality. J Am Geriatr Soc 2000;48:1292-1299.

7. Loeb M, McGeer A, McArthur M et al. Risk factors of pneumonia and other lower respiratory tract infections in elderly residents of long-term care facilities. Arch Intern Med 1999;159:2058-2064.

8. Lim WS, Macfarlane JT. A prospective comparison of nursing home acquired pneumonia with community acquired pneumonia. Eur Respir J 2001;18: 362-368.

9. Torres $\mathrm{OH}$, Munoz J, Ruiz D et al. Outcome predictors of pneumonia in elderly patients: Importance of functional status. J Am Geriatr Soc 2004 1991; 52:1603-1609.

10. McGeer A, Campbell B, Emori TG et al. Definitions of infection for surveillance in long-term care facilities. Am J Infect Control 1991;19:1-7.

11. Herbert R, Carrier R, Bilodeau A. The Functional Autonomy Measurement System (SMAF). Description and validation of an instrument for the measurement of handicaps. Age Ageing 1988;17:293-302.

12. Hebert R, Spiegelhalter DJ, Brayne C. Setting the minimal metrically detectable change on the disability rating scales. Arch Phys Med Rehabil 1997; 78:1305-1308. 
13. Charlson ME, Pompei P, Ales KL et al. A new method of classifying prognostic comorbidity in longitudinal studies: Development and validation. J Chronic Dis $1987 ; 40: 373-383$.

14. Fine MJ, Auble TE, Yealy DM et al. A prediction rule to identify low-risk patients with community-acquired pneumonia. N Engl J Med 1997;336: 243-250.

15. Zemen FD, Wallach K. Pneumonia in the aged. An analysis of 166 cases of its occurrence in patients 60 years old and over. Arch Intern Med 1946;77:678.

16. Verghese A, Berk SL. Bacterial pneumonia in the elderly. Medicine 1983;60:271-285.

17. Bentley DW. Bacterial pneumonia in the elderly: Clinical features, diagnosis, etiology and treatment. Gerontology 1984;30:297-307.

18. Fein AM, Feinsilver SH, Niederman MS. Atypical manifestations of pneumonia in the elderly. Clin Chest Med 1991;12:319-337.

19. Esposito AL. Community-acquired bacteremic pneumococcal pneumonia: Effect of age in manifestations and outcome. Arch Intern Med 1984;144: 945-948.

20. Marrie TJ, Haldane EV, Faulkner RS et al. Community-acquired pneumonia requiring hospitalization: Is it different in the elderly? J Am Geriatr Soc 1985; 33:671-680.

21. Marrie TJ, Blanchard W. A comparison of nursing home-acquired pneumonia patients with patients with patients with community-acquired pneumonia and nursing home patients without pneumonia. J Am Geriatr Soc 1997;45: $50-55$.
22. Meehan TP, Chua-Reyes JM, Tate J et al. Processes of care performance, patient characteristics, and outcomes in elderly patients with community-acquired or nursing home-acquired pneumonia. Chest 2000;117:1378-1385.

23. Jansenns JP, Gauthey L, Herrman F et al. Community-acquired pneumonia in older patients. J Am Geriatr Soc 1996;44:539-544.

24. Inouye SK, Peduzzi PN, Robison JT et al. Importance of functional measures in predicting mortality among older hospitalized patients. JAMA 1998;279: 1187-1193.

25. Mayer-Oakes SA, Oye RK, Leake B. Predictors of mortality in older patients following medical intensive care: The importance of functional status. J Am Geriatr Soc 1991;39:862-868.

26. Mehr DR, Foxman B, Colombo P. Risk factors for mortality from lower respiratory infection in nursing home patients. J Fam Pract 1992;34:585-591.

27. Binder EF, Kruse RL, Sherman AK et al. Predictors of short-term functional decline in survivors of nursing home-acquired lower respiratory tract infection. J Gerontol A Biol Sci Med Sci 2003;1A:M60-M67.

28. Marrie TJ, Huang JQ. Low risk patients admitted with community-acquired pneumonia. Am J Med 2005;118:1357-1363.

29. High KP, Bradley S, Loeb M et al. A new paradigm for clinical investigation of infectious syndromes in older adults: Assessment of functional status as a risk factor and outcome measure. Clin Infect Dis 2005;40:114-122.

30. Dedier J, Singer DE, Chang Y et al. Processes of care, illness severity, and outcomes in the management of community-acquired pneumonia in academic hospitals. Arch Intern Med 2001;161:2099-2104. 